\title{
Research on Linyi Tourism Brand Strategy Based on the Advantage of Cultural Resources
}

\author{
Shi Yunli \\ Feixian Campus, Linyi University \\ Linyi, Shandong, China \\ 15165519838@163.com
}

Keywords: Linyi City; Cultural resources; Tourism; Strategy; Innovation

\begin{abstract}
Comparative advantage and competitive advantage are two basic elements of regional culture and tourism core competitiveness. The requirements of seizing the opportunity and considering tourism industry as the pillar industry need us break through the traditional patterns based on the facts of Linyi City. Based on developing cultural tourism resources in Linyin, the paper put forward suggestions on the construction of tourism brand.
\end{abstract}

\section{Present Tourism Development Status of Linyi}

In recent years, the tourism industry in Linyi city has achieved a rapid development; the main economic indicators continue to grow, and the image of geological tourism, eco-tourism, red tourism, urban tourism has been preliminarily established. However, according to the requirements of the scientific development concept, the development of Linyi tourism has a lot of questions to be settled compared to developed areas all over the country.

Present Status of Linyi Tourism Resources Products. The tourism resources in Linyi own the characteristics of rich and diversity content, wide distribution, a variety of types, high-ranking taste, profound cultural background and distinctive local features, which have not only a large variety of green tourism resources, but also a lot of red tourism resources famous all over the country; not only historical cultural resources known to the world, but also a variety of agricultural tourism resources; not only famous commerce logistics tourism, but also colorful modern tourism resources. All these have laid a solid foundation for the development of the tourism industry in Linyi. In recent years, Linyi city has developed a number of competitive tourism projects owning Linyi characteristics, rich in cultural connotation which has been recognized by the tourism markets. The development of tourism resources formed four themes: Green Yimeng Red customs, Military Expertise, Geological Wonders" and embodied product system rich in leading cultural elements. The situation of culture and tourism interactive win-win has been appeared.

Linyi City Tourism Industry System has been Initially Formed. At present, there are a total amount of 34 national A-level tourist areas, of which 4A-level 4, 3A-level 14. The amount of national A-level tourist areas and the total number of 4A high level tourist areas respectively stand second and third places in Shandong province. Fourteen industrial and agricultural tourism demonstration sites have been set up which rank the fourth in Shandong Province, among which the national industrial and agricultural tourism demonstration sites are 8 and the provincial 6 . There are 16 Star-rating restaurants, ranking third in the province, of which five-star 2 and four-star 2 . There are 12 travel agency, ranking ninth in the province, including 2 international travel services, 92 domestic travel services. The amount of tourism direct practitioners are more than 60,000 people, tourism related practitioners reach nearly 300,000 people. Tourism management service reception system and the "big tourism" industry development pattern have been formed in Linyi which own the characteristics of relatively perfect supporting system, normative service and covering "eat, housing, transportation, travel and purchase" these six elements. 
Linyi Tourists and Tourism Revenue Grow Obviously. In 2013, under the guidance of building Linyi into a city with powerful tourism economy and red tourism, Linyi city accelerated the construction of the project, improved infrastructure and strengthened the promotion of tourism industry which had shown good development trend. The city received 4,760.950,000 domestic and foreign tourists, realizing the total number of tourism revenue 413.77 billion Yuan, accounting for $9.9 \%$ of the proportion of the city's GDP. As of the end of 2013, the city's total number of National A-class tourist areas are 55, including 1 5A-level area and 14 4A-level ones; starred hotel are 61, of which 4 four-star Hotel; travel agencies are 95; the provincial tourism county are 4 and tourism 8 Town Tourism Village 9; the national industrial and agricultural tourism demonstration sites are 8, and the provincial one are 21; tourism practitioners reached more than 500,000 people.

\section{Strategic Significance of Cultural Tourism Integration Development}

From the successful experience of cultural tourism development, regions with rapid development of the tourism industry are those that the culture is fully mined and inherited. The regions with developed culture industry are where tourism function is perfect and has an unlimited appeal to visitors. The requirements of economy and culture need to mine culture resources to develop tourism industry, embody tourism products with rich culture connotations. Cultural industry development needs to develop tourism market share and achieve economic, social and ecological benefits.

Comparative advantage and competitive advantage are the two basic elements of regional culture and the core competence of tourism. The better and faster development of Linyi tourism needs to complete the breakthrough and evolution of "culture". Compared the comparative advantage and competitive advantage with Tai'an, Jining and Rizhao, Linyi is lower and only by extracting the cultural quality and creating a cultural tourism high-end boutique project can we attract more tourists, so as to promote the prosperity and development of culture and tourism.

Excavation of History and Culture is an Objective need to Enhance the Attractiveness of Tourism. From the motivation when international and domestic tourists choosing the destination of tourism, we can infer that experiencing history and culture is of the first choice. It is a makingmonkey project to accelerate the development of tourism that we protect and dig the local history and culture to enhance the thick texture of a place and promote its attraction to tourists. The project needs to develop the historical and cultural resources as the whole, create cultural tourism products and embody cultural connotation to tourism products. So that we can better present fresh local cultural atmosphere so that the majority of tourists would infiltrate in the local characteristics of culture through tourism, experiencing the feelings deep in the soul from the process of travel experience. And the charming and attraction of the place would be strengthened, too. Tourists would gain experience rising to the soul from eyes and feel the shock of Yimen culture. Therefore, important steps of enhancing the attraction of Linyi and maintaining the sustainable development of tourism are to dig and carry forward Linyi history and culture to enhance feelings toward them. The digging of Linyi history and culture resources can be finished by the mutual integration of tourism culture to promote the mutual integration between the tourism industry and the cultural industry and by creating products, cultivating high-quality goods, displaying characteristics to accelerate the mutual prosperity.

Carrying Forward the Characteristic Culture is the Objective need of Constructing the Tourism Competitiveness. Any place has its own historical process. The new characteristics and personality characteristics would be derived by the time. This kind of feature and personality is not selective and be born with, which eventually become the symbol of a place, the spring of travel competitiveness, and an important destination and attraction for tourists. After the accumulation of history and the creation of a comprehensive tourism culture boutique, cultural characteristics of Linyi tourism is prominent, with rich species and high level. Special cultural resources advantage of "Yimeng spirit" as the core, such as red culture, saint culture, military culture, holy wisdom culture, hot spring culture, business culture, Yimen entertainment culture, Yimeng folk culture and so on, has 
become Yimeng characteristics and gotten the praise of domestic and foreign tourists. The culture of "The saint", "holy wisdom", with its unique calligraphy, art of war, bamboo slips resources attract a lot of tourists, which take culture as the soul of tourism, tourism as the carrier and form tourism products with unique characteristics of Yimeng culture. The Sky King City with its unique cultural resources of King $\mathrm{Ji}$, and the unique $\mathrm{Gu}$ cultural resources owns novel ideas and distinctive features. Mengshan with leisure culture forms unique longevity culture. These cultures all make Linyi tourism image more thick, the theme more distinctive and the combination of point, line and surface more reasonable, highlighting the charm of Linyi tourism, which attract tourists and provide a strong guarantee for the building of cultural and tourism core competitiveness.

Cultivating Modern Culture is the Objective need of the Driving Force of the Conservation of Tourism. Human is the first factor to create and spread for tourism and culture. Building an open culture and at the same time sticking to the characteristics of culture enable the development of the tourism industry to maintain adequate support and stamina and constitute a driving force for the development of local tourism. The beauty that tourists gained after tourism is pleasant, natural, cultural and social one which requires that the local tourism development must rely on its own historical and cultural characteristics, play the advantages of culture, build their own modern culture with an open mind.

While in the guarantee of the history and culture, humanities should be guaranteed to advance with the times and to ensure the harmonious development of the times. Jiangquan enterprise, New times medicine enterprise, Lan Ling ancient town, Guilaizhuang gold deposit, Yinmai Beer Industrial Park, Cangshan Dai village, Nine tents and so on as the representative of the industrial and agricultural tourism demonstration sites, through the development of tourism promote the enterprise culture, highlight the new tourism and allow visitors to be shaken in mind. With the development of economy and society, the modern culture covers more extensively; the content is more rich and varied and the development is more rapid, such as culture and modern tourism enterprise culture, modern scientific culture, green environmental protection culture, modern urban culture, new rural culture, screen culture, wine culture, self-driving culture, people oriented civil literacy and hospitality and the construction of destination tourism information environmental atmosphere and so on. Practice has proved that modern culture is the engine. Through the excavation of cultural connotation, the core of the modern tourism culture is to build core competitiveness of culture and tourism.

\section{Comparative Advantage of Cultural Resources in Linyi City}

Through tourism, Chinese culture could be spread and promoted. The integration of tourism and cultural industries could be promoted and the new achievements of the development of Chinese tourism industry could be displayed, too, which would enhance the overall tourism image of china. The revolution culture and red tourism as important parts of Chinese culture will become a theme with intense melody. From the formation of the industrial system and its industrial scale, although Linyi tourism started late, it developed quickly. With the increasing popularity of Linyi tourism, "the natural landscape, kinship Yimeng" is gradually recognized by the market. The goals of creating the best leisure tourism city all over the country and the most important tourism area in the south of Shandong and north of Jiangsu or even all over Shandong Province are increasingly distinct. The goals of construction of tourism economy city, red tourist city emerged.

From the perspective of Shandong Province, the province's tourism has formed famous tourism brand image: the "Spring City" Ji'nan, "the capital of sailing ship" Qingdao, Taishan mountain "the capital of kite" Weifang and many others as representatives. Especially the five city in the south of Shandong Province, ie, Lunan Economic Belt, has formed "hometown of Kong Meng" Jining, "hometown of peony" Heze, " Yimeng good scenery" Linyi," "Oriental bridgehead harbor "Rizhao," hometown of railway guerrilla "Zaozhuang and other famous tourism brand image. In the series of 
famous city tourism brand image, the development of Linyi tourism has the following obvious comparative advantages:

Natural Peculiar Ecological Tourism Resources.Natural peculiar ecological tourism resources in Linyi include Mengshan natural ecological tourism resources, Yishui ecological tourism of caverns geological wonders, Feixian Yimeng stone forest tourism zone, Junan Buddha tourist area. Especially Mengshan tourism resources, the main peak of guimeng is the second highest peak in Shandong with excellent natural ecological environment and high brand awareness. Yishui ecological tourism of caverns geological wonders developed quickly, known as Yishui tourism phenomenon, and was a dark horse in the development process of tourism industry. Feixian Yimeng stone forest is the only large amount of stone landscape in the north of Yangtze River. Junan Buddha is the holy Buddhist culture in the south of Shandong and north of Jiangsu.

Historical and Cultural Resources. Linyi city is the hometown of the famous St. Wang Xizhi, St. Zhu Geliang, St. Liu Hong and the great calligrapher Yan Zhenqing. Yinque mountain bamboo slips museum and the ancient stone relief tomb own specific resources and are famous home and abroad. Linyi historical and cultural resources gathering together with high grade has a good historical and cultural resources development advantages.

Red Tourism Resources. Linyi ciryi is the core area of Yimeng old revolutionary base areas, the carrier of Yimeng red culture tourism, and the core of the development of Shandong red tourism. Yimeng spirit connotation is rich with strong local characteristics and an important part of the cultural spirit of the Chinese nation. The red tourism resources of Linyi city are unique with high visibility and strong attraction. Menglianggu Battle Memorial, Yimeng Revolutionary History Museum and the Eight Route Army 115 division headquarters site (the setting up of provincial government memorial) and other tourist areas have become scale.

Urban Tourism Development Advantages. Linyi city has a unique comparative advantage of developing urban tourism. Its tourism resources are rich and unique, which include riverside scenic spot, the former residence of Wang Xizhi, Yinqueshan bamboo slips museum, Yimeng Revolutionary History Museum, zoo and botanical gardens, ShengNeng amusement park, the International Film City which have great attractive for tourists. It is a newly livable city with developed commercial logistics and masses of floating population.

The Advantage of Hot Spring Tourism Resources. Linyi city has high-quality spa tourism resources. Yishui, Yinan and Hedong District are rich in hot spring tourism, forming a hot spring tourism leisure zone. Hot spring tourism is a high-end luxury leisure travel form and will be one of the important projects of tourism industry development. Hot spring tourism resources develop by clustering and is unmatched by other cities around Linyi. Comparative advantages of reliance development of Linyi tourism is obvious, but Linyi lies in the note or edge position in the landscapeSaint tourism route (Taishan-Qufu-Qingdao, or Qufu-Ji'nan-Taishan) or Qufu-Rizhao, Linyi City. Especially with the operation of Chinese Culture Symbolic City in Qufu and "the capital of water sports" in Rizhao, Jining and Rizhao will show a strong development momentum and the rapid development of regional tourism put pressure on Linyi city tourism development. The urgent need of the development of Linyi tourism industry needs to develop innovation strategy. The implementation of strategic innovation in the tourism industry to build a practical tourism system in Linyi City is an urgent need to enhance the competitiveness of tourism development in Linyi City.

\section{Some Suggestions on the Construction of Tourism Brand in Linyi}

Strengthen Regional Cooperation in Tourism and Form a Joint Force of Tourism Development. In our country, the development of tourism cooperation in the Yangtze River Delta, Pearl River Delta and other regions of is more mature and accumulated a lot of valuable experience, but more is to stay in the level of spontaneous push. From now on, it is necessary to take the initiative to intervene from the national level. According to the actual situation of important priority areas during 
the period of the $13^{\text {th }}$ Five Year Plan, the promotion of further deepening of regional cooperation in tourism and regional coordinated development need do the followings. First of all, establish a consultative mechanism. Local government should establish the daily coordination of tourism cooperation organization formulate the tourism cooperation norms, convene regular joint and irregular meetings with high-level personnel to participate in and research and consult the direction and form of tourism cooperation. Secondly, the government should establish mechanisms for information exchange, open up the information communication channels through the Internet or the establishment of information transmission platform, strengthen the communication between government departments and enterprises. At the same time, tourists can gain direct travel information more conveniently, more comprehensively and more directly. Thirdly, the government should establish a market reciprocity mechanism. By jointly organizing tourism festival activities, jointly developing tourism routes, jointly designing and developing unique geographical characteristics of tourism products, etc., government and tourism industry should break the barriers of the market, send customers to each others, market externally and create the overall tourism image.

Cultural industry and tourism industry planning in Linyi city usually have a style of their own because of lack of necessary relevance among each county, which is small but comprehensive and hard to form an overall advantage. According to the resources characteristics and other conditions of each county, these two industries should undertake the characteristic orientation, give full play to the comparative advantages and avoid low-level redundant construction and vicious competition. The characteristic orientation and comparative advantage should be adhered to, relying on the key areas construction of Linyi city and each county and further playing its leading role and radiation function. For a period of time, a major priority task of the development of culture and tourism industry in Linyi is actively seeking cooperation outside the city and abroad and promoting trans-regional cooperation. Each county should abandon their development and management habits under the guidance of traditional concept of competition, break the country blockade, weaken the concept of border, strengthen the ideas of trans-regional cooperation and mutual benefit and win-win, adhere to the overall idea of characteristics and complementation in process of the development and design of products. We should change the current status of lacking unified planning and monitoring in the culture and development of tourism products, construct effective mechanism to break the barriers between different regions and industry and according to the different characteristics of the project regarding the high-ranking projects as leaders, achieve the integration of superiority resources of related areas and industries.

Bringing Regional Advantages into Play and Making the Molding of the Yimeng Culture Tourism Brand the Key Element. To make full use of regional advantages, we should dig deep into the connotation of regional culture and make the regional characteristic culture as the key elements of tourism brand shaping. At the same time, centering on food, living, travel, shopping and entertainment these six elements, we should create a series of unique, international tourism products and brands in line with market's further understanding, recognition and acceptation to regional tourism characteristics. We should construct a unique regional tourism brand from the connotation and denotation of the brand. On the one hand, we should speed up the construction of new, world-class landmark tourism projects and tourism facilities, take the application and construction of the best tourism city, national 5A-level scenic spots, five-star hotel and other well-known brands as an opportunity to launch a series of competitive tourism city brand, tourism scenic area brand, tourism hotel brand, the travel agency brand and create a large number of inter provincial tourism lines with distinct features, market attractiveness.

Through the mobilization of tourism projects, the promotion of tourism functions and the improvement of tourism services, we can constantly optimize the core of regional tourism brand. On the other hand, from the perspective of brand denotation, we should realize the brand communication based on the image carrier. We should extract the regional tourism image, and regard the system of tourism image with regional characteristics as support to design the regional tourism slogan, symbol, 
and mascot and so on. Through the creative design and marketing promotion plan, we should mould outstanding and unique tourism with profound influence from inside to outside.

Integrate Cultural Tourism Resources and Become Well-known with "Yimeng tourism" Brand. The adherence to the integrated development of cultural resources and tourism resources required to go stereo marketing road and become well-known with "Yimeng tourism" brand. Culture needs to develop the cultural industry market and realize the mutual promotion and interaction of the cultural tourism through the tourism market that has been formed and the mature marketing network. Firstly, tourism sectors should hire tourism experts to carry out the overall image design and packaging to some important scenic spots. Secondly, tourism sectors should hold a series of activities with Linyi characteristics, such as the use of festivals of "Sage Longevity Cultural Festival', cultural tourism exhibitions, seminars and so on. Thirdly tourism sectors should carry out a unified collection of trademarks, naming, evaluation, registration and other activities, improve Linyi tourism culture connotation, to further expand and enhance the visibility of Linyi tourism through the media news reporters invited to news exploration, shooting scenery documentary, holding the famous painting and calligraphy masters and culture celebrities site creation, painting, writing stories and other activities. Fourthly tourism sectors engage in the development of tourist commodities and souvenirs, deep mining, processing and packaging with distinctive scenic folk arts and crafts, native products to meet the needs of tourists shopping, which turn the passers into tourists, tourists into diners, diners into lodgers, lodgers into customers, focusing on the "food, housing, transportation, travel, shopping, entertainment" to improve the comprehensive benefits of tourism.

Pay Attention to the Innovation of Characteristic Resources and Tourism Products and Strengthen the Cultural Connotation of Tourism Products. Tourism products should have unique atmosphere, which vary from place to place, from man to man and change with times. Linyi tourism product culture should be promoted from the artistic conception and combined with the three levels: one is to include the past, respect for the past and carry forward the past; two is to focus on the reality, studying the history of culture to be applied to today use; three is to guide the future, develop the future. Strategic vision should be owned at macro level and we should do it from the reality at micro level. We should establish the concept of "big product". Through the high level of creative combination, we can change the habit that simply attaches importance to the development of resources and neglect of cultural connotation. Development and sales of tourism products firstly need to have a strong cultural connotation. The new development of any tourism products should reflect its unique cultural connotation. Secondly, we should pay attention to the tourism products innovation of cultural connotation. In tourism services, we should strengthen the service awareness of tourism culture, pay attention to the cultural system and reflect the high quality of culture. Culture is often reflected in the subtle aspects and social benefits. So in order to strengthen the cultural connotation of tourism products, we must take the construction of cultural tourism characteristics as the goal, highlight the culture as the focus, take "overall planning, step by step development, highlighting focus, reflecting characteristics, market-oriented, rational utilization" as the principle to highlight local cultural characteristics, cultural connotations and details, formulate and plan the overall planning and detailed planning of cultural tourism . To maintain the seriousness of the planning, we should prevent the emergence of constructive destruction and destructive construction.

Excavate and Display Culture and Form the Product Characteristics Packaging. The cultural features of Linyi tourism focus on the excavation, the core on the project package. We should rely on the existing resources, pack carefully a number of projects reflecting cultural atmosphere and the historical characteristics project, enhance the project's ornamental and participatory. Linyi cultural tourism takes "Yimeng spirit" as the core, "green Yimeng, red style, military expertise, geological wonders" as the theme, makes the brand and slogan of "natural landscape, family Yimeng" and "Yimeng good place" be known, highlights characteristics of the knowledge, participation, displays modern technology, advanced technology and unique technology advantages and expands market circulation. Agricultural tourism should highlight the local flavor, highlight the local characteristics, 
national characteristics and other advantages, continue to dig, collect and collate folk culture, etc., combine and utilize the development of agricultural tourism, create characteristic villages, folk villages and other forms to display and continue valuable folk culture. Tourism culture products focus on unique features. Because the tourists with the aspirations and needs of "novelty, curiosity, seeking pleasure" is difficult to be appealed to if there are no characteristics and therefore it can not form market competitiveness. "Music and dance of Tang Dynasty " in Shanxi Xi'an, "Dragon phoenix dance of the Chinese" in Shenzhen overseas Chinese town, "Almond altar holy dreams" in Shandong Qufu, "Shanxi songs" in Shanxi Taiyuan, "Erdos wedding" in Inner Mongolia, " Acrobatics world" in Hebei Wuqiao, "Fjard of flourish time" in the Three Gorges Dam, "Ya Gong hospitality" in Tibet, all have distinctive national culture and geographical culture characteristics, many of these works are unique and distinct. "The nation is the world", from this point of view, Linyi city in the planning of tourism culture product packaging has not yet formed a distinctive feature of the market.

Stick to Planning and Coordination and Promote the Social Development of the Tourism Industry. In accordance with the requirements of "forming the integration pattern of urban and rural economic and social development", we should balance urban-rural tourism development, lay stress on the development of the rural tourism, red tourism and eco-tourism, and bring the role of tourism in the construction of new socialist countryside into full play. The role of tourism industry in the development of culture should be played, too. We should strengthen the ideological and moral education of tourism practitioners, pay attention to the promotion of socialist core values in the process of tourism to make tourism become an important channel for the promotion of advanced culture. The fact that culture is the soul of tourism urges us continuously improve the cultural content of tourism products, actively explore the cultural tourism resources, explore and cultivate the new form of the close combination of tourism and culture, promote the traditional culture through tourism, cultural tourism through new vitality to achieve greater development.

In short, we should adjust the tourism industry structure, especially the tourism product structure, change the current status of tourism products laying stress on natural landscape sightseeing, tourism consumption on tourism consumption, tourism competition on low-level price competitive, improve the cultural connotation and scientific and technological content, increase tourism products and tourism projects with strong participation, interaction, enhance the tourism shopping, leisure, vacation, business and other functions, improve the comprehensive economic benefits, so as to improve the utilization rate of resources, avoid waste of resources and realize the sustainable development of tourism.

\section{Reference}

[1] Shi Yunli. Research on the exploration and utilization of red tourism resources in Linyi [J]. Modern Business Trade Industry. 2011(5)

[2] Shi Yunli. Research on red tourism marketing strategy based on government level [J].China Business \& Trade, 2011.5.

[3] Linyi city annals office. The history of Linyi city [M]. Beijing: Zhonghua Book Company,2001.11

[4] Liu Jianping, Zou Yan. Development of red tourism scenic sightseeing agriculture development in Shanshan[J]. Journal of Hunan city university, 2010(4)

[5] Chen Ganghua, Huang Yuanshui. Empirical research of the influence factors of tourist revisit decision-making---based on network investigation[J]. Tourism Tribune 2008, 11:69-74.

[6] Wang Bin, $\mathrm{Wu}$ Chunyou, Li Zhendong. A Comparative Analysis of First-time and Repeat Visitors' behavior[J]. Areal research and development. 2009,28(3):68-71.

[7] Yang Yang, Zhang Jie, Zhao Ningxi, A study on tourists' travelling experience in tourist destinations and revisit intention--- A case study of Yixing[J]. Tourism Tribune. 2008.5:42-48. 
[8] Chen Ganghua, Huang Yuanshui. Influencing factors on tourists' revisit decision-making: A web-based empirical study [J]. Tourism Tribune, 2008(11).

[9] Bai kai, Guo Shengwei. An empirical study on the impact of symbiotic image in scenic areas on tourists' willingness of revisit and their words of mouth effect---A case study on Qnjiang scenic areas with the theme of Tang culture in Xi' an [J]. Tourism Tribune, 2010(01).

[10] Geng Xianhui, Wang Xiaoqing, Sun Qiaosheng. Eco-tourism, tourist satisfactionand revisit will: A case study of future agro-park in Suzhou China [J]. Ecological Economu, 2010 (06) . 